\title{
Temperature Resistance of the Boundary Lubrication Layers Under Rolling with Slippage Condition
}

\author{
Tareq M. A. Al-Quraan ${ }^{1, ~ *}$, Oksana O. Mikosyanchik ${ }^{2}$, Rudolph G. Mnatsakanov ${ }^{3}$ \\ ${ }^{1}$ Technical Sciences Department, College of Ma'an, Al-Balqa Applied University, Al-Salt, Jordan \\ ${ }^{2}$ Life Safety Department, National Aviation University, Kiev, Ukraine \\ ${ }^{3}$ Organization of Aviation Works and Services Department, National Aviation University, Kiev, Ukraine
}

\section{Email address:}

tarjor999@gmail.com (T. M. A. Al-Quraan), oksana.mikos@bk.ru (O. O. Mikosyanchik), mnatsakanov@bk.ru (R. G. Mnatsakanov) *Corresponding author

\section{To cite this article:}

Tareq M. A. Al-Quraan, Oksana O. Mikosyanchik, Rudolph G. Mnatsakanov. Temperature Resistance of the Boundary Lubrication Layers Under Rolling with Slippage Condition. International Journal of Mechanical Engineering and Applications. Vol. 5, No. 2, 2017, pp. 78-86. doi: 10.11648/j.ijmea.20170502.12

Received: February 9, 2017; Accepted: February 21, 2017; Published: March 7, 2017

\begin{abstract}
The influence of slip velocity at rolling with slippage on the intensity of heat release in the local contact at different modes of lubricating action was examined. Efficiency of using different procedures for calculating a temperature increase in the friction contact under conditions of dominating elastohydrodynamic and boundary modes of lubricating action was shown. The interrelation between the processes of heat release intensity in tribotechnical contact and wear of friction pairs was established. It was analyzed that the locality of the increased wear in the central section of the contact line is determined by a change in the stress-strained surface condition at friction and by the occurrence of stress concentrator center.
\end{abstract}

Keywords: Contact Temperature, Heat Release Intensity, Boundary Layer, Lubrication Mode, Wear

\section{Introduction}

Under conditions of the tribosystem transition into critical operation modes, which include increased loads, high slip velocities, non-stationary operating conditions ("start-stop" regime), there appears a probability of disruption of continuity of the lubricant film. In this case, the passage from the hydro- and elastohydrodynamic mode to the boundary mode of lubricating action in contact is possible. Heat removal from the friction zone is considerably disrupted under such conditions; the local sections, which are characterized by a sharp increase in temperature, occur in contact. Due to discretion of the friction contact, friction connections are formed on the actual contact spots during friction process, each of which can exist within a very short time interval and disappears when the contact in this place is disrupted. Thus, physical processes, which cause frictional force and thermal phenomena and wear, connected with it, appear in the zone of actual contact.

The existing variety of procedures for determining heat release intensity in the tribotechnical contact does not consider the possibility of periodic change in friction modes, which occur at the transition of tribosystem into the critical operating modes.

Thus, the problem of selection of high precision numerical methods for the interpretation of results of practical studies for the purpose of further approval of the given methods in real friction nodes proves to be rather relevant. In particular, the establishment of interrelation of the processes of heat release intensity in the tribotechnical contact and the wear of friction pairs is an important task, which makes it possible to solve the problems, connected with the prediction of the operating resource of friction pairs with the local form of contact.

\section{Literature Review and Problem Statement}

Friction is the process of conversion of energy. According to [1], the conversion of external mechanical energy into the energy of internal processes occurs in the process of friction. An estimation of energy processes at friction on the 
macrolevel by friction loss factor is proposed in this work. This parameter reflects the dissipative nature of the friction process, taking into account energy losses in a tribosystem. Friction loss factor depends not only on the properties of contacting bodies, but also on the load, slip velocity, environmental conditions and others.

In papers [2-4], the conversion of friction contact energy into strain energy, destruction energy and thermal energy was simulated on the basis of the first law of thermodynamics. Under slipping conditions, due to strain, maximum distribution of the released heat is concentrated in the surface layer and is sharply decreased with an increase in the distance from the contact surface.

In temperature problems of friction, it is questionable to use Fourier's one-dimensional equation of thermal conductivity with constant coefficients of thermal conductivity, heat capacity, density and thermal diffusivity of materials of the contact surfaces in connection with highspeed and heavily loaded friction nodes [5]. However, authors present a procedure, according to which the calculations of thermal processes in the most diverse and most specific constructions of friction nodes are proved experimentally, as well as by the predicted wear of friction pairs in them $[6,7]$.

Linear correlation between wear and scattered energy is established in articles [8-10]. Furthermore, the quantity indicator of energy dissipation can be considered as an indicator of changes in mechanical and structural properties of the contacting bodies.

The application of lubricants creates prerequisites for effective heat removal from the friction zone.

Paper [11] proposes a model of temperature prediction in the linear contact, taking into account the exponential rheological dependence of the non-Newtonian behavior of a lubricant.

Work [12] presents development of an analytical model for predicting friction coefficient in the linear contact at thermal elastic-hydrodynamic lubrication (TEHL). A new theoretical equation for determining friction coefficient taking into account the rheological properties of lubricants is proposed. This approach considers heat release in contact and heat propagation in the depth of contacting bodies. It was established that the mean temperature in the lubricant film is the total of such components as flash temperature increase, a temperature increment due to internal heating of a film and the value of lubricant temperature at the entry into contact [13].

The model, proposed in [14], examines temperature distribution within the contact zone of two rough surfaces. An analysis of the roughness influence on an increase in the local temperature in the contact zone is given in paper [15]. The largest increase in temperature reaches approximately $220^{\circ} \mathrm{C}$ over the area of about $3 \%$ of the nominal contact area. The mean temperature within the contact zone is in the range from 150 to $220^{\circ} \mathrm{C}$.

A divergence in the calculations of temperature increase in contact at friction in the process of lubricant degradation at seizure of contact surfaces, which is determined according to the chemical kinetic model and the mechanical model, may amount up to $100^{\circ} \mathrm{C}[16]$.

Thus, it follows from the presented analysis of scientific literature on the problem of estimation of the temperature state of tribotechnical contact that there is no a unified approach to the selection of the procedure of calculation of temperature in contact. The existing methods of evaluation of the influence of temperature factor on the state of a lubricant film are based on the main principles of elastohydrodynamic theory of lubrication. However, for friction pairs with the local contact, which include tooth gears, the operating conditions relate predominantly to non-stationary systems (a cyclic change "start-stop"). In this case, in the process of one operating cycle, the lubrication mode may vary from half dry to hydrodynamic. Due to this, the use of only elastohydrodynamic criteria during the estimation of temperature in contact is not entirely correct. A more correct systematic approach is enhancing reliability of estimation of parameters of the thermal condition of tribotechnical contact via an analysis of increase in temperature under the boundary friction conditions. Specifically, parameters of the boundary lubrication mode are prevailing in the prediction of anti-wear characteristics of contact.

Taking into account the aforementioned, the study of processes of heat release in tribotechnical contact under conditions of tribosystem operating under different lubrication modes is undoubtedly of scientific and practical interest.

\section{Purpose of the Work}

The purpose of present work is establishment of the dominant factors, which influence heat release in the local contact under different lubrication modes under conditions of rolling with slippage.

\section{Procedure of the Experiment}

The developed procedure for the evaluation of temperature stability of the boundary films of a lubricant includes the following:

- To conduct running-in of the contact surfaces under non-stationary friction conditions ("start - stop" regime) in the automated tribotechnical complex whose basic characteristics are described in paper [17];

- To create conditions of abundant lubricant feeding into the friction zone at the contact pressure by Hertz (100 $500 \mathrm{MPa}$ ) under conditions of rolling with a different degree of slippage (from 3 to $40 \%$ );

- To perform running-in of the friction pairs and to achieve subsequent operating time before the stabilization of the basic tribotechnical indicators of contact (thickness of lubricant film at rest, at start-up and in the period, which corresponds to the selected maximum rolling velocities of advancing and lagging surfaces; friction coefficient; specific friction work), 
which characterize the formation of a stable boundary layer by the components of the lubricant;

- To terminate feeding of lubricant into the friction zone, to remove the residues of lubricant from the contact surfaces with a rag;

- To register a change in the basic tribotechnical indicators of contact before the manifestation of the first signs of seizure of contact surfaces;

- To carry out an estimation of conditions for the occurrence of jamming by the critical temperature in the contact zone of the elements of tribological conjunction.

We used rollers, made of steel 1045 (HRC 38, Ra 0.57 $\mu \mathrm{m})$, as samples. The lubrication of contact surfaces was conducted by dipping the lower roller into the tray with oil. Mineral transmission oil Okko GL-4 80w/90 for mechanical gearboxes and main drives of passenger cars and trucks was used as a lubricant. Volumetric temperature of oil was $20^{\circ} \mathrm{C}$.

Maximum rotation frequency for the advancing surface was $1000 \mathrm{r} / \mathrm{min}$. In present paper, the slippage of 3, 10, 20, 30 and $40 \%$ was simulated. Maximum contact stress by Hertz was $250 \mathrm{MPa}$.

A running-in of the contact surfaces in 100 cycles and the subsequent work of friction pairs in 200 cycles were performed under conditions of abundant oiling, after which, over subsequent 100 operating cycles, the lubricant feeding was terminated. Starting with the 400th cycle, the oil deficiency mode was created - The forced removal of the lubricant from the contact surfaces by wiping rollers with a rag.

\section{Estimation of Factors that Influence the Heat Release Intensity in the Friction Contact}

According to [18], the heat release intensity in the friction zone depends on friction power and is determined by relationship:

$$
\mathrm{Q}_{\mathrm{r}}=\mathrm{fN}_{\mathrm{l}} \mathrm{V}_{\mathrm{sl}} \text {, }
$$

Where $\mathrm{f}$ is the friction coefficient, $\mathrm{N}_{\mathrm{l}}$ is the load per unit of length, $\mathrm{V}_{\mathrm{sl}}$ is the slip velocity.

Let us examine a change in the heat release intensity for the studied surfaces under conditions of rolling with a different degree of slippage. With a sufficient lubricant feeding into the contact zone, when the effective heat removal is achieved, the heat release intensity increases on average by 40 times at an increase in slippage from 3 to $40 \%$ "Fig. 1". More intensive heat release is established under conditions of rolling with slippage, which exceeds $20 \%$. It should be noted that independently of the degree of slippage of contact surfaces, the examined transmission oil is characterized by high lubricating qualities:

The formed thickness of the lubricant film reaches on average 5-6 $\mu \mathrm{m}$.

According to the calculation criterion of determining a mode of lubricating action: $\lambda=\frac{\mathrm{h}}{\sqrt{\mathrm{R}_{\mathrm{a} 1}^{2}+\mathrm{R}_{\mathrm{a} 2}^{2}}}$, in contact, independently of the slippage degree, the hydrodynamic mode of lubricating action is implemented. Thus, the surfaces are separated by the sufficient amount of the lubricant, which is an important regulator of the heat balance in the tribosystem.

However, in formula (1), only antifriction properties of oil are taken into consideration. The obtained experimental data prove an increase in friction coefficient on average by 2.2 times with an increase in degree of slippage from 3 to $40 \%$ under conditions of sufficient lubricant feeding into the contact zone. However, this parameter does not entirely reflect the change, which takes place in the lubricant film with an increase in slip velocity.

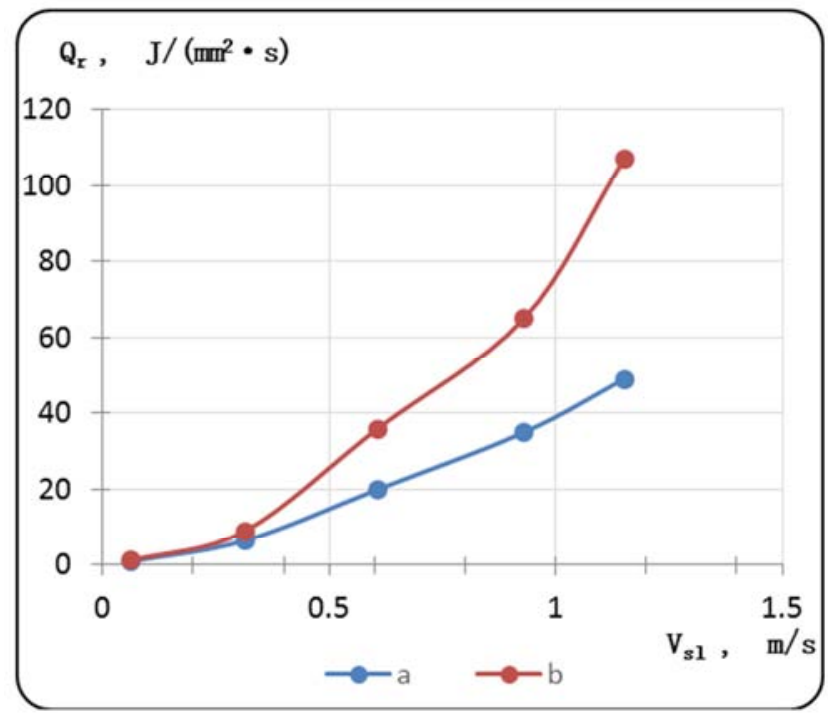

Figure 1. Heat release intensity in the friction contact: $a$-under conditions of abundant lubricant feeding to the friction zone; $b$ - under conditions of termination of lubricant feeding to the contact surfaces.

Specifically, an increase in $\mathrm{V}_{\text {ск }}$ by 18 times in the studied slippage range is the leading factor, which causes a change in rheological properties of the lubricant [19]. The boundary lubricant films of different nature are formed at the contact surfaces, activated by friction, which is a prerequisite for the separation of the lubricant film into hydro- and nonhydrodynamic components. Therefore, it is necessary to run a more detailed analysis of the factors, which influence the heat release intensity in the friction contact.

In the experiment, after the 400th cycle of operating time, the lubricant was forcedly removed from the contact surfaces. Under such conditions, hydrodynamic component of thickness of the lubricant film does not exist. Therefore, basic lubricating, antifriction and anti wear properties of the tribocontact are determined by the resistance of boundary lubricant films to mechanical and temperature influences. A sharp fluctuation in the thickness of the lubricant film was observed, which led to stiffening of friction conditions, which are manifested by the implementation of half-dry, boundary and mixed modes of lubricating action "Table 1". 
Under conditions when hydrodynamic component of thickness of the lubricant film is absent, tangential shear stresses are localized in the structured boundary layers, which possess other rheological properties in comparison with the volumetric phase.

This leads to an increase in friction coefficient on average by 2 times, in comparison with the conditions of sufficient lubricant feeding into the contact zone for all studied contact surfaces independent of the slippage degree. Accordingly, parameter $\mathrm{fN}_{\mathrm{l}} \mathrm{V}_{\mathrm{sl}}$ in formula (1), characterizing friction power, increases similar to the change in friction coefficient.

Table 1. Dependence of thickness of lubricant film in the contact on the magnitude of slippage under conditions of rolling.

\begin{tabular}{ll}
\hline Slippage, $\%$ & $\begin{array}{l}\text { Thickness of lubricant film under conditions of forced } \\
\text { oil removal, } \boldsymbol{\mu m}\end{array}$ \\
\hline up to 3 & $0,23-4,7$ \\
10 & $0,23-4,6$ \\
20 & $0,19-4,5$ \\
30 & $0,13-4,3$ \\
40 & $0-3,2$ \\
\hline
\end{tabular}

An increase in friction power causes increased heat release in the contact. The heat release intensification occurs at $\mathrm{V}_{\mathrm{sl}}>$ $0.6 \mathrm{~m} / \mathrm{s}$, which corresponds to the slippage of the lagging surface of $20-40 \%$ "Fig. 1". This is the leading factor, contributing to

the desorption of boundary lubricant films, a decrease in the non-hydrodynamic component of thickness of the lubricant film and, as a result, to an increase of the danger of jamming the contact surfaces.

\section{Calculation of Heat Release in the Lubricant Film under Conditions of Hydrodynamic and Elastohydrodynamic Modes of Lubricating Action}

Let us analyze the equation of energy balance for a lubricant [20] under conditions of hydro- or elastohydrodynamic mode of lubricating action, which considers the rheological and physical characteristics of oil:

$$
\mathrm{dQ}_{\mathrm{r}}^{*}=\mathrm{dQ}_{\mathrm{rem}}+\mathrm{dQ}_{\mathrm{a}},
$$

Where $\mathrm{dQ}_{\mathrm{r}}^{*}$ is the heat release in the lubricating layer of elementary thickness, $\mathrm{dQ}_{\mathrm{rem}}$ is the heat removal into neighboring lubrication layers, $\mathrm{dQ}_{\mathrm{a}}$ is the heat amount consumed for heating lubricating material in the friction zone.

Let us assume that

$$
\begin{gathered}
d Q_{r}^{*}=\tau l \frac{\partial u}{\partial y} d y=\mu \frac{\partial u}{\partial y} l \frac{\partial u}{\partial y} d y=\mu l\left(\frac{\partial u}{\partial y}\right)^{2} d y \\
d Q_{r e m}=\lambda_{0} l \frac{\partial^{2} t^{0}}{\partial y^{2}} d y \\
d Q_{a}=c_{0} \rho_{0} V_{s l} l \frac{\partial t^{0}}{\partial x} d y
\end{gathered}
$$

Where $\tau$ is the tangential shear stress of lubricant film, $\frac{\partial u}{\partial y}$ is the gradient of shearing rate, $\mu$ is the dynamic viscosity, $\rho_{0}$ is the lubricant density, $c_{0}$ and $\lambda_{0}$ are specific heat and coefficient of thermal conductivity of the lubricant.

Then equation of energy balance will be written down in the form:

$$
\mu\left(\frac{\partial \mathrm{u}}{\partial \mathrm{y}}\right)^{2}=\lambda_{0} \frac{\partial^{2} \mathrm{t}}{\partial \mathrm{y}^{2}}+\mathrm{c}_{0} \rho_{0} \mathrm{~V}_{\mathrm{sl}} \frac{\partial \mathrm{t}^{0}}{\partial \mathrm{x}}
$$

In paper [20], in the process of calculating the temperature of the lubricant film, the following assumptions are accepted:

- Heat removal in the friction surface can be disregarded;

- Temperature across the lubricant film is constant;

- Lubrication temperature changes only lengthwise the lubricant film.

If the temperature across the lubricant film is constant, then

$$
\frac{\partial \mathrm{t}^{0}}{\partial \mathrm{y}}=0, \frac{\partial^{2} \mathrm{t}^{0}}{\partial \mathrm{y}^{2}}=0
$$

Consequently, the temperature will change only lengthwise the lubricant film:

$$
\frac{\partial \mathrm{t}^{0}}{\partial \mathrm{x}}=\frac{\mathrm{dt}^{0}}{\mathrm{dx}}
$$

According to the accepted assumptions, the equation of energy balance will take the form:

$$
\mu\left(\frac{\partial u}{\partial y}\right)^{2}=c_{0} \rho_{0} V_{s l} \frac{\partial t^{0}}{\partial x}
$$

If we assume that $y=h$, where $h$ is the thickness of the lubrication layer, $\mathrm{u}=\mathrm{V}_{\mathrm{sl}}$, then

$$
\begin{aligned}
& \frac{\partial \mathrm{u}}{\partial \mathrm{y}}=\frac{1}{2 \mu} \frac{\mathrm{dp}}{\mathrm{dx}}(2 \mathrm{y}-\mathrm{h})+\frac{\mathrm{V}_{\text {ск }}}{\mathrm{h}} \\
& =\frac{1}{2 \mu}\left(6 \mu \mathrm{V}_{\sum \mathrm{r}} \frac{\mathrm{h}-\mathrm{h}_{0}}{\mathrm{~h}^{3}}\right)(2 \mathrm{y}-\mathrm{h})+\frac{\mathrm{V}_{\mathrm{sl}}}{\mathrm{h}}= \\
& =\frac{\mathrm{V}_{\text {ск }}}{\mathrm{h}}\left[3 \frac{\left(\mathrm{h}-\mathrm{h}_{0}\right)(2 \mathrm{y}-\mathrm{h})}{\mathrm{h}^{2}}+\frac{\mathrm{v}_{\mathrm{sl}}}{\mathrm{v}_{\Sigma \mathrm{r}}}\right] .
\end{aligned}
$$

Based on the indicated assumptions, after integration $\int_{0}^{\mathrm{h}} \mu\left(\frac{\partial \mathrm{u}}{\partial \mathrm{y}}\right)^{2} \mathrm{dy}$ and transformations, according to [20], the formula for determining the increment in temperature in the lubrication layer:

$$
\Delta \mathrm{t}^{0}=\int_{\mathrm{x}_{1}}^{\mathrm{x}} \frac{2 \mu \mathrm{V}_{\mathrm{sl}}}{\mathrm{c}_{0} \rho_{0} \mathrm{~h}_{0} \mathrm{~h}}\left[3\left(\frac{\mathrm{h}-\mathrm{h}_{0}}{\mathrm{~h}}\right)^{2}+\left(\frac{\mathrm{V}_{\mathrm{sl}}}{\mathrm{V}_{\mathrm{r}}}\right)^{2}\right] \mathrm{dx} .
$$

Based on the obtained experimental data about rheological characteristics of the studied transmission, we established the heat release dynamics in the lubricant film according to analytical dependences by formulas (3-6). At low slip velocities (up to $0.3 \mathrm{~m} / \mathrm{s}$ ), which corresponds to slippage of up to $10 \%$, the heat release in the lubricant film is insignificant, the maximum indicators of this parameter are 12 J/s "Fig. 2". 
In this case, the maximum increase in temperature of the lubricant, according to formula (10), reached $2-3^{\circ} \mathrm{C}$. A rapid increase in the heat release was established at slip velocity exceeding $0.6 \mathrm{~m} / \mathrm{s}$. However, the maximum increment in temperature is insignificant and reaches $10^{\circ} \mathrm{C}$.

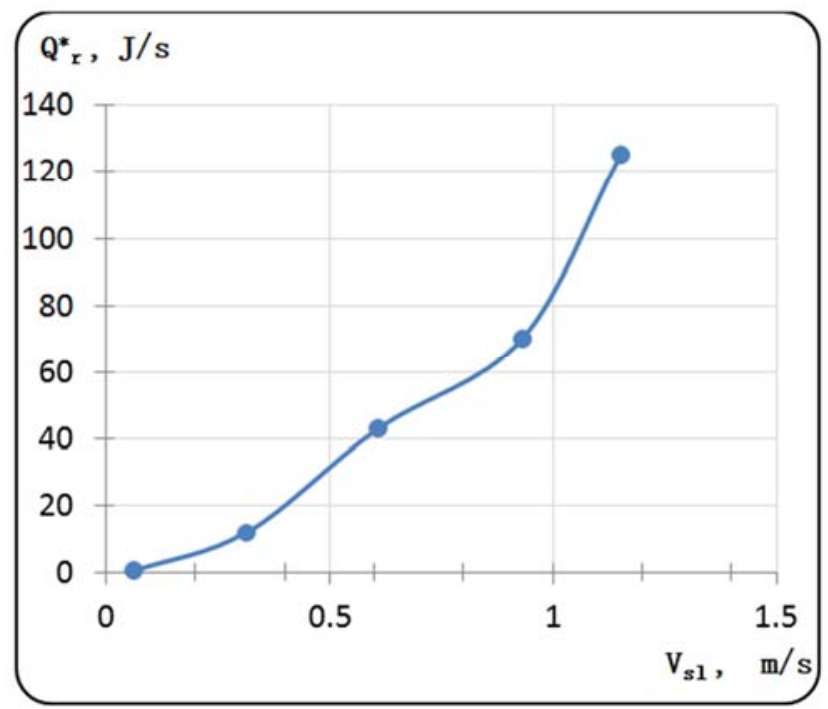

Figure 2. Dependence of heat release in the lubricant film on the magnitude of slippage under conditions of rolling.

Thus, the given analysis of heat release in the lubricant film according to the formula (6) under conditions of rolling with slippage shows that the intensive heat removal is achieved under the hydro- and elastohydrodynamic mode of lubricating action, an increase in temperature in contact is insignificant. Therefore, the lubricant decreases friction power loss when there is an effective lubricant film ( $h \gg$ $\mathrm{R}_{\mathrm{a}}$ ), which significantly decreases heat release intensity in the contact "Fig. 1".

At $\mathrm{h} \ll \mathrm{R}_{\mathrm{a}} ; \mathrm{h} \rightarrow 0$ under conditions of half-dry and boundary modes of lubricating action, it is difficult to calculate heat release in the lubricant layer by formulas (26). An increment in temperature (by formula 10) in the boundary layer of the lubricant at $\mathrm{h}<0,5 \mu \mathrm{m}$ reaches 400 $500^{\circ} \mathrm{C}$. In our opinion, these indicators are rather overstated as they considerably exceed the flash temperature of the studied lubricant.

\section{Calculation of Heat Release in the Friction Contact under Conditions of Boundary Mode of Lubricating Action}

Under conditions of half-dry and boundary mode of lubricating action it is proposed to use the following procedure for calculating the critical temperatures and to accept the following assumptions.

At the destruction of boundary lubricant films, there occurs a local increment in temperature on the discrete sections during the friction interaction. The studied contact model "roller - roller" is the source of heat generation in the form of additive totality of the point heat generation sources, connected along the contact line "Fig. 3".

According to [18], for the conditions of rolling with slippage, the intensity of heating of the advancing and lagging surfaces depends on the total velocities of rolling and slipping. Under conditions close to jamming, there is a rapid temperature increment of the lagging roller in comparison with the advancing roller, in this case the speed of temperature increment depends on the velocity mode, loading and very little on the radius of the curvature.

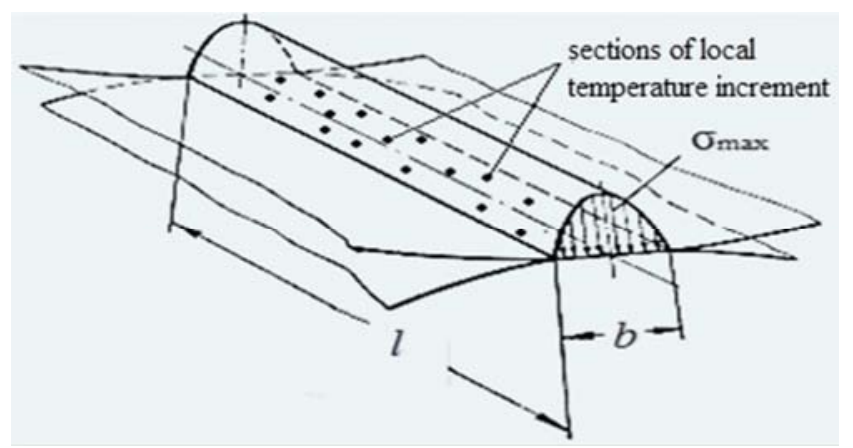

Figure 3. Schematic of friction contact during the work of friction pairs under conditions of rolling with slippage.

The magnitude of temperature increment depends on the ratio of velocity of motion of bodies and coefficient of thermal conductivity, that is, on number $\mathrm{P}_{\mathrm{e}}$. Let us introduce the $\mathrm{P}_{\mathrm{e}}$ criterion (a Pecle number), which characterizes the relation of heat content of the flow of axial direction to the heat flow in the transverse direction and is determined by relationship:

$$
\mathrm{P}_{\mathrm{e}}=\frac{\mathrm{vl}}{\mathrm{a}_{\mathrm{t}}}
$$

Where $\mathrm{V}$ is the velocity, $\mathrm{l}$ the length of contact lines of surfaces, $a_{t}$ is the coefficient of thermal conductivity, which is determined by ratio:

$$
\mathrm{a}_{\mathrm{t}}=\frac{\lambda}{\rho \mathrm{c}}
$$

Where $\rho$ is the specific metal weight, $\mathrm{c}$ is the specific thermal capacity of metal, $\lambda$ is the metal coefficient.

Since in the studied contact model the velocity of rolling of the advancing surface is constant and makes $2.75 \mathrm{~m} / \mathrm{s}$, the velocity of the heat source, according to the $\mathrm{P}_{\mathrm{e}}$ criterion, will be determined by the velocity of slip at the existence of slippage of the contact surfaces:

$$
\Delta \mathrm{P}_{\mathrm{e}}=\mathrm{P}_{\mathrm{e} 1}-\mathrm{P}_{\mathrm{e} 2}=\frac{\mathrm{V}_{1} \mathrm{l}}{\mathrm{a}_{\mathrm{t}}}-\frac{\mathrm{V}_{2} \mathrm{l}}{\mathrm{a}_{\mathrm{t}}}=\frac{\left(\mathrm{V}_{1}-\mathrm{V}_{2}\right) \mathrm{l}}{\mathrm{a}_{\mathrm{t}}}=\frac{\mathrm{V}_{\mathrm{sl}} \mathrm{l}}{\mathrm{a}_{\mathrm{t}}} .
$$

Where $V_{1}, V_{2}$ are the velocities of rolling of advancing and lagging surfaces respectively, $\mathrm{V}_{\mathrm{sl}}$ is the velocity of slip.

At the minimum studied $3 \%$ slippage of the lagging surface, number $\Delta \mathrm{P}_{\mathrm{e}}$ is 2.08. An increase in the degree of slippage causes a correlation increase in the $\mathrm{P}_{\mathrm{e}}$ criterion: $\Delta \mathrm{P}_{\mathrm{e}}$ at slippage of $40 \%$ reaches 39.93 .

According to the hypothesis, put forward by H. Blok [21], for each pair of tribological conjunction and the type of a lubricant, there is a critical temperature, at exceeding of 
which a seizure or jamming of contact surfaces occurs as a result of the loss of the protective anti wear properties by a lubricant. In this case, the criterion to evaluate the conditions for jamming occurrence is the critical temperature in the contact zone of the elements of the tribological conjunction, which is expressed by dependence:

$$
\mathrm{t}_{\Sigma \mathrm{cr}}=\mathrm{t}_{0}+\vartheta
$$

Where $t_{0}$ is the temperature of surfaces prior to the entrance into the contact zone, $\vartheta$ is the flash temperature, which is an instantaneous temperature increase, at which jamming occurs.

No-jamming condition is satisfied at

$$
\mathrm{t}_{0}+\vartheta \leq \mathrm{t}_{\Sigma \mathrm{cr}}=\mathrm{const}
$$

Where $t_{0}$ is defined experimentally, $\vartheta$ is defined by calculation.

Under condition of equality of initial temperatures of contact surfaces of cylindrical shape, an instantaneous increment in temperature $\vartheta$ is determined from formula:

$$
\vartheta=0,83 \frac{\mathrm{fN}_{\mathrm{l}} \mathrm{V}_{\mathrm{sl}}}{\left(\sqrt{\lambda_{1} \rho_{1} \mathrm{c}_{1} \mathrm{~V}_{\mathrm{r} 1}}+\sqrt{\lambda_{2} \rho_{2} \mathrm{c}_{2} \mathrm{~V}_{\mathrm{r} 2}}\right) \sqrt{\mathrm{b}}}
$$

Where $\mathrm{f}$ is the friction coefficient, $\mathrm{N}_{\mathrm{l}}$ is the load per unit of length, $V_{\mathrm{sl}}$ is the velocity of slip; $\lambda_{1,2}$ is the coefficient of thermal conductivity, $\rho_{1,2}$ is the specific weight, $c_{1,2}$ are the specific thermal capacity of the advancing (1) and lagging (2) surfaces, respectively; $b$ is the half-width of the contact area by Hertz.

According to formula (16), parameter $\mathrm{fN}_{\mathrm{l}} \mathrm{V}_{\mathrm{sl}}$, which characterizes friction power and heat release in the contact, has the largest influence on an instantaneous increase in temperature in the contact zone under conditions of nonstationary work of triboelements. At slippage of contact surfaces up to $10 \%$, a local increase in temperature is insignificant both under conditions of the abundant lubricant feed into the friction zone and under conditions of oil deficiency "Fig. 4".

Parameter $t_{0}+\vartheta \ll t_{\Sigma c r}$ was not established because of the seizure of contact surfaces.

At the further increase in the degree of slippage, as it was analyzed above, there occurs an increase in friction power. Local increment in temperature increases on average by 3 and 7 times at slippage of 20 and $40 \%$, respectively, under conditions of abundant oiling. However, sufficient lubricant feeding into the friction zone creates prerequisites for the effective heat removal.

Under conditions of oil deficiency, the local increase in temperature exceeds the analogous parameter at $10 \%$ slippage by 4 times (slippage 20\%) and by 13 times (slippage $40 \%$ ). The first signs of seizure of contact surfaces are observed at the local increase in temperature up to $125^{\circ} \mathrm{C}$ in the 490th (slippage 20\%) and at the local increase in temperature up to $410^{\circ} \mathrm{C}$ in the 415 th cycle (slippage $40 \%$ ). Based on the obtained experimental data, it is possible to estimate the temperature stability of boundary layers. It corresponds to minimum temperature $t_{\Sigma c r}$, at which the first signs of seizure of contact surfaces appear. For the studied lubricant, this parameter reaches $145^{\circ} \mathrm{C}$.

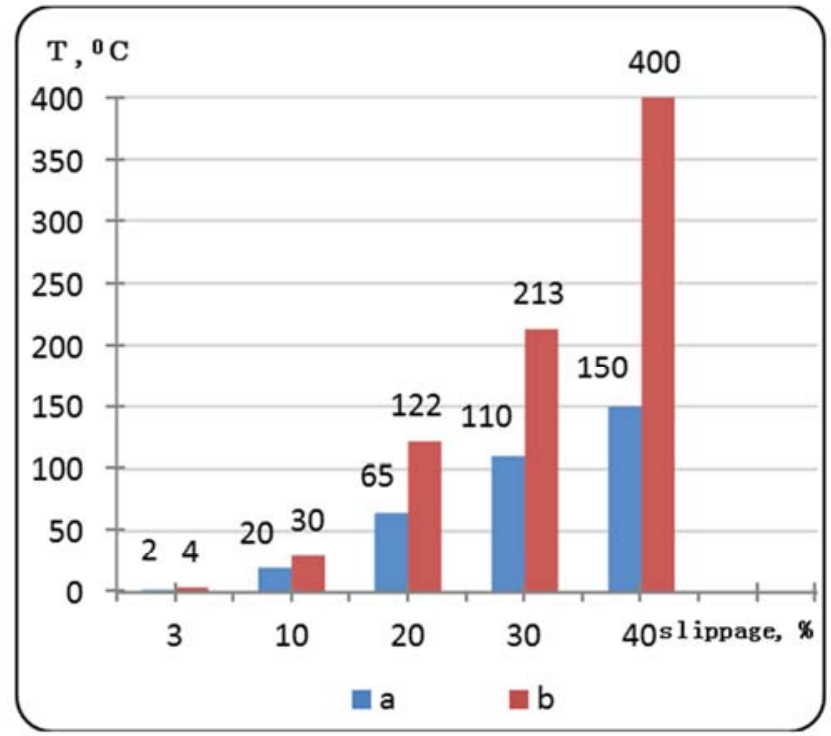

Figure 4. Local increase in temperature in the friction contact: a-abundant lubricant, $b$ - oil deficiency.

\section{Influence of Temperature and Mechanical Action on the Wear of Contact Surfaces}

Authors in papers [22-24] underline a high temperature stability of the boundary lubricant films, which may reach 90- $400^{\circ} \mathrm{C}$, depending on the type of additive and the base. However, under conditions of slippage, a decrease in critical temperature of the destruction of boundary layers is observed due to the simultaneous effect of temperature and gradient of shearing rate. The existence of plastic deformations of contact surfaces also leads to a decrease in the critical temperature of destruction of boundary layers [25].

Article [26] proposes a synergetic model, in which melting of a lubricant film occurs due to the mechanisms of thermodynamic and shearing influence. As for the studied processes of lubricating action under the non-stationary friction conditions, it is possible to model the basic stipulations of this theory in the following way. Under conditions of rolling with slippage, critical temperature $t_{\Sigma \mathrm{cr}}$, at which jamming occurs, depends, first of all, on slip velocity. With an increase in velocity of slip the gradient of the shearing rate of lubricant films increases and elastic strains reach the critical value, at which there occurs destruction of boundary layers through their melting. Thus, the gradient of shearing rate of lubricant films is the leading factor of the mechanical destruction of lubricant films. Simultaneously, an increase in slip velocity causes an increase in temperature in contact and, as a result, thermal destruction of boundary layers. The synergism of the influence of the given processes is pronounced in sharp fluctuations of thickness of the lubricant film and friction coefficient, an increase in specific work of friction, a 
decrease in effective viscosity of the lubricant. These changes in tribotechnical characteristics of contact testify to the disruption of the structural adaptability of a tribosystem, its passage into the non-equilibrium state, which leads to the manifestation of the first signs of seizure of contact surfaces and shortening of the period of normal operation of triboelements.

Results of wear measurement of advancing and lagging surfaces along the line of their contact testify to the nonuniformity of wear of friction pairs "Fig. 5"

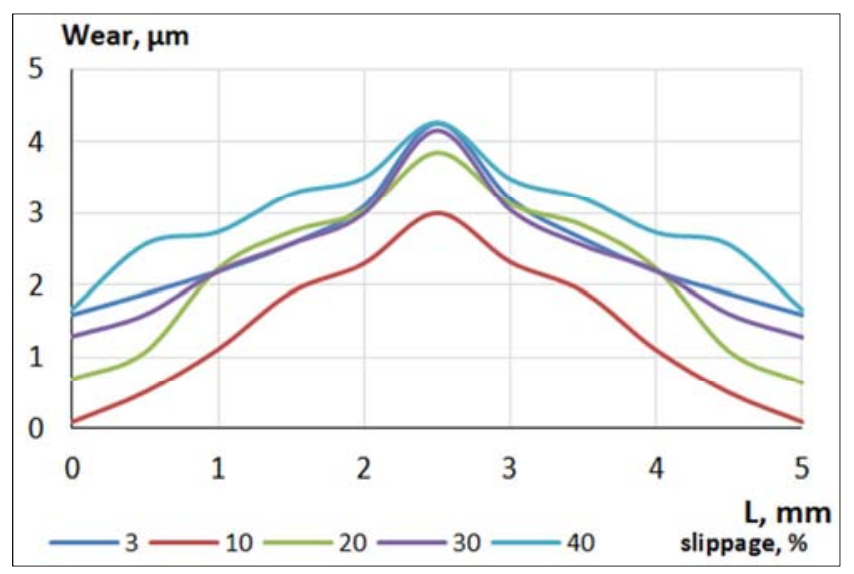

a)

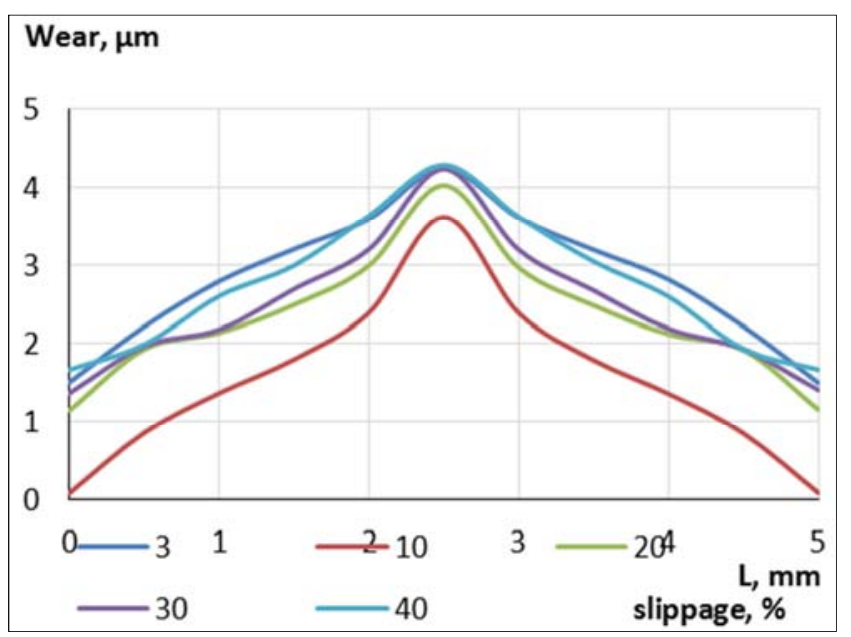

b)

Figure 5. Curve of wear of friction pairs along the contact line: a) advancing surface; b) - lagging surface.

The curve of wear distribution with the maximum in the central contact zone and the minimum on the periphery is observed distinctly. In this case, the wear in the central zone exceeds the wear of contact surfaces in the sections outermost from the center on average by 2.8 times. We assume that a local increase in the wear in the central contact zone of surfaces is a direct consequence of the simultaneous influence of stresses and maximum temperatures.

An increase in the energy balance of tribosystem under mechanical influence due to an increase in slip velocity at slippage, localization of shearing stresses in the thin nearsurface layers create the gradient of temperatures both in the depth and along the length of the contact as a result of decrease in the intensity of the processes of heat exchange with the environment, which leads to the change in their mechanical properties. However, temperature gradient on the surface of metal creates stresses, which during the imposition of shearing stresses lead to loosening of material and to increased wear in the central section along the contact line, whereas the most intensive hardening of the material occurs along the depth in the same zone "Fig. 6"

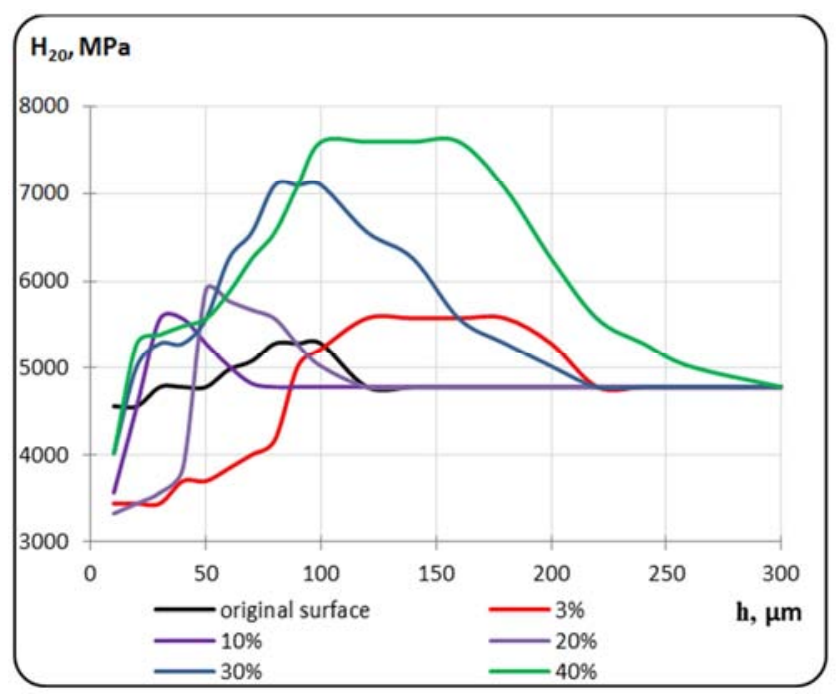

Figure 6. Distribution of microhardness along the depth in the central zone of friction contact for lagging surface after friction with rolling with slippage from 3 to $40 \%$.

An occurrence of the zone of local increased wear in the contact leads to changing the stress-strained states of surfaces and appearance of the center of stresses concentrator.

The simulation of contact with the use of method of final elements (the Nastran program) makes it possible to calculate the fields of temperatures and stresses in the studied samples. To simulate heat release into the environment, the following boundary conditions were used: ambient temperature was accepted equal to $20^{\circ} \mathrm{C}$, initial temperature of samples was considered equal to ambient temperature. The calculations, made with the use of this technique, showed that the maximum values of temperatures and equivalent temperature stresses were characteristic for the central zone along the contact line of the surfaces "Fig. 7".

For example, an increase in temperature from $120^{\circ} \mathrm{C}$ to $400^{\circ} \mathrm{C}$ leads to an increase in the equivalent temperature stresses from 220 to $600 \mathrm{MPa}$, respectively, at slippage of 20 and $40 \%$.

It is in the central section of the contact line that the first signs of seizure of contact surfaces arise at $20-40 \%$ slippage under conditions of the forced removal of lubricant from the contact zone "Fig. 8".

Authors of paper [27] established a manifestation of the zones of maximum local wear along the meshing line of tooth gear, or "the weakest" zones, which depend on temperature in the contact: pitting is manifested in the zones 
of predominant influence of rolling velocity rather that slipping velocity, whereas jamming occurs in the zones of maximum velocities of slip.

Results of our studies under non-stationary friction conditions make it possible to complement the ideas about the structural-energy state of the zones of maximum local wear. With the minimum slippage (up to $3 \%$ ), which is analogous to the circumpolar zone of tooth gear meshing, the processes of fatigue failure of plastic secondary structures dominate, which are characterized by low indicators of specific friction work, minimum increment in the temperature, resistance to seizure under conditions of insufficient lubricant feeding into the contact zone. With an increase in slippage up to $20-40 \%$, which corresponds to circumpolar zones of tooth gear meshing, the processes of destruction of durable secondary structures are characterized by high indicators of specific friction work, an increase in temperature in contact, hardening of the surface and nearsurface layers of metal, and the tendency toward seizure under conditions of limited lubricating action.

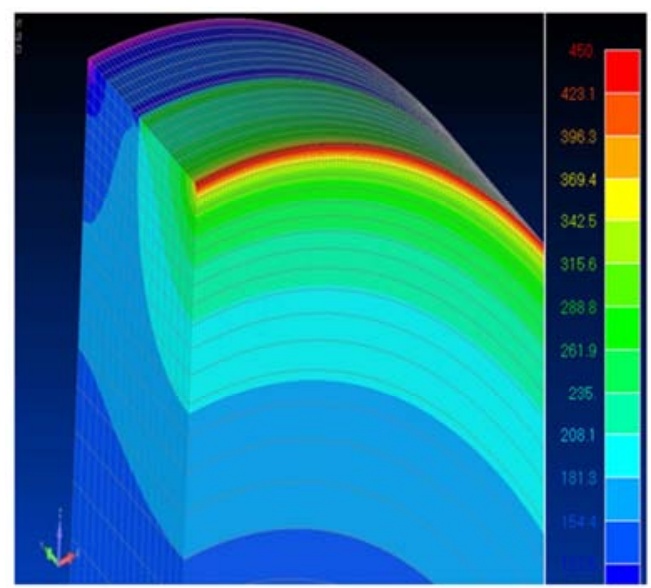

a)

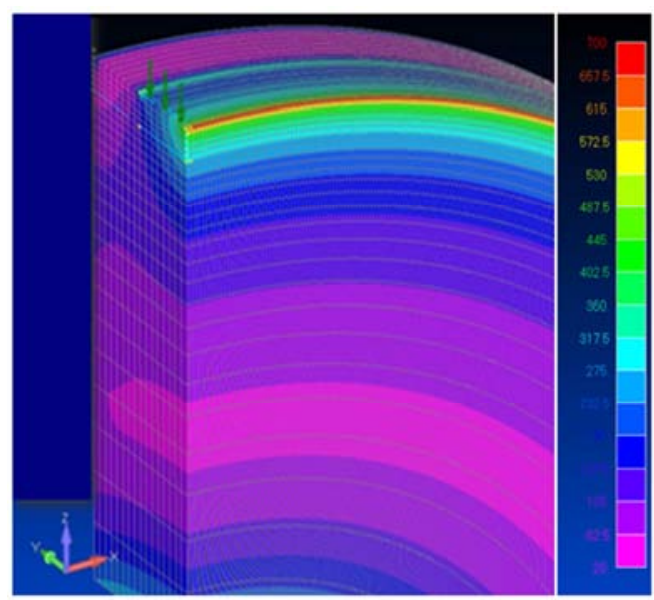

b)

Figure 7. Change in temperature (a) and equivalent temperature stresses (b) along the line of friction contact (cross-section through the center of the friction path of the studied sample).

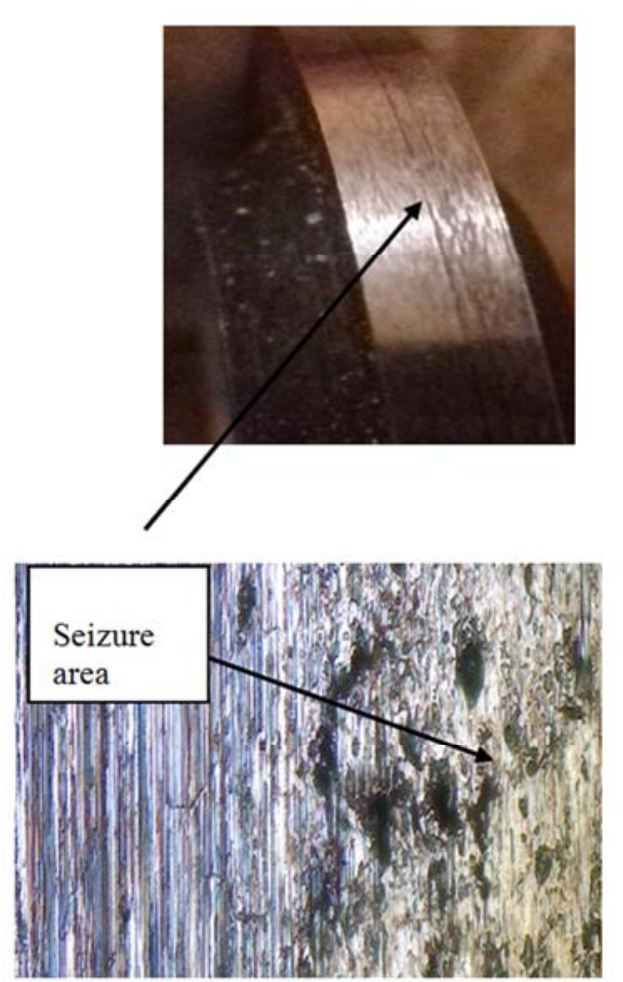

Figure 8. Seizure section of contact surfaces, located in the central zone along the line of friction contact.

\section{Conclusions}

The influence of the magnitude of slippage of contact surfaces on the kinetics of change in heat release intensity in contact is established. More intensive heat release is characteristic for the conditions of rolling with slippage, which exceeds $20 \%$. Under conditions of termination of lubricant feeding into the friction zone, we observed an increase in heat release intensity on average by 2 times for the friction pairs, which work at slippage of $20-40 \%$. This is caused by the destruction of boundary films of a lubricant, which results in the decrease of heat removal.

The dynamics of heat release in the lubricant film was analyzed taking into account the rheological characteristics of a lubricant in the contact. The expediency of selection of different procedures of calculation of an increase in temperature in the friction contact under dominating conditions of hydrodynamic, elastohydrodynamic and boundary modes of the lubricating action was demonstrated.

The mechanisms, which cause the influence of temperature and mechanical actions on the stress-strained state of the surface at friction, were established. We analyzed the influence of the given factors on the occurrence of the stress concentrator center and a zone of the local increased wear in the contact.

\section{References}

[1] Rymuza C. (1996) "Energy concept of the coefficient of friction", Wear, Vol. 199, pp. 187-196. 
[2] Q. Chen, D. Y. Li, (2005) "A computational study of frictional heating and energy conversion during sliding processes", Wear, Vol.259, pp.1382-1391.

[3] K. Elalem, D. Y. Li, M. J. Anderson, S. Chiovelli, (2001), "Modeling abrasive wear of homogeneous and heterogeneous materials", ASTM STP, Vol.1339, pp. 90-104.

[4] Q. Chen, D. Y. Li. (2004) "Investigation on the mechanisms of corrosive wear process of alloy with a micro-scale dynamic model", Mater. Sci. Eng. A, Vol.369, pp. 284-293.

[5] V. A. Balakin, Yu. V. Lysenok (2001) "Teplovydelenie i teploperenos v zone frikcionnogo kontakta", Vestnik GGTU im. P. O. Suhogo, № 1, S.3-7.

[6] Balakin V. A., Galaj E. I. (2000) "Raschet prirasheniya temperatury v obode kolesa zheleznodorozhnogo podvizhnogo sostava", Trenie i iznos, T. 21, №3, S. 269-275.

[7] V. A. Balakin (1981) "Formation and distribution of heat in the frictional contact zone under conditions of non-stationary heat exchange", Wear, Volume 72, Issue 2, pp 133-141. http://dx.doi.org/10.1016/0043-1648(81)90363-X.

[8] Jahangiri M. (2014) "Investigation of the Slipping Wear based on the Rate of Entropy Generation", Journal of Modern Processes in Manufacturing and Production, Vol. 3, No. 1, pp. $47-57$.

[9] R. Colaco, M. P. Gispert, A. P. Serrob, B. Saramago (2007) "An energy-based model for the wear of UHMWPE", Tribol. Lett., Vol. 26, pp. 119-124.

[10] K. E. Nurnberg, G. Nurnberg, M. Golle, H. Hoffmann (2008) "Simulation of wear on sheet metal forming tools-An energy approach", Wear, Vol. 265, pp. 1801-1807.

[11] A. Mihailidis, J. Retzepis, C. Salpistis, K. Panajiotidis, (1999) "Calculation of friction coefficient and temperature field of line contacts lubricated with a non-Newtonian fluid", Wear, Vol. 232, Issue 2, pp. 213-220. http://dx.doi.org/10.1016/S0043-1648(99)00148-9.

[12] Echávarri Otero, J., de la Guerra Ochoa, E., Chacón Tanarro, E., Díaz Lantada, A., and Munoz-Guijosa, J. M.(2016), "Analytical model for predicting friction in line contacts", Lubrication Science, 28: 189-205. doi: 10.1002/1s.1325.

[13] Echávarri J, Lafont P, Chacón E, de la Guerra E, Díaz A, Munoz-Guijosa JM, Muñoz JL. (2011) “Analytical model for predicting friction coefficient in point contacts with thermal elastohydrodynamic lubrication", Proceedings IMechE Part J: Journal of Engineering Tribology, 225, pp.181-191.

[14] Lee, S. C. and Cheng, H. S. (1992) "On the relation of load to average gap in the contact between surfaces with longitudinal roughness", Tribology Trans., 35 (3):523-529.

[15] Stephen M. Hsu, Richard S. Gates (2000) "Boundary Lubrication and Boundary Lubricating Films", Chapter 12, P.484-485. DOI: 10.1201/9780849377877.ch12 - in book: Modern Trybology Hendbook. Volume One. Principles of Tribology. - Editor-in-Chief Bharat Bhushan / CRC Press, 1760p. ISBN 0-8493-84030-6/.
[16] S. M. Hsu, M. C. Shen, E. E. Klaus, H. S. Cheng, P. I. Lacey, "Mechano-chemical model: Reaction temperatures in a concentrated contact", Wear, Vol. 175, Issues 1-2, pp. 209218.

[17] T. M. A. Al-quraan, O. O. Mikosyanchik, R. G. Mnatsakanov, 2016, "The Effect of the Slippage Degree at Rolling with Slipping on the Wear Resistance of Contact Surfaces", Mechanical Engineering Research; Vol. 6, No. 2; 2016, pp. 48-61. doi:10.5539/mer.v6n2p48.

[18] Drozdov Yu. N., Archegov V. G., Smirnov V. I.(1981) "Protivozadirnaya stojkost trushihsya tel", M.: Nauka, 275c.

[19] Mikosyanchyk O., Mnatsakanov R., Zaporozhets A., Kostynik R., 2016, "Influence of the nature of boundary lubricating layers on adhesion component of friction coefficient under rolling conditions", Eastern-European Journal of Enterprise Technologies, 4/1 (82), pp. 24-31. doi:10.15587/17294061.2016.75857.

[20] E. P. Zhilnikov, V. N. Samsonov (2012) "Osnovy tribotehniki: uchebn. dlya vuzov" Samara: izd-vo Samar. gos. aerokosm. un-ta, 136s. ISBN 978-5-7883-0919-4.

[21] Blok H., 1939,,Seizure-delay" method for determining the seizure protection of E. P. lubricants", SAE J. (Trans.), Vol. 44, № 5, p.193.

[22] Matveevskij R. M., Buyanovskij I. A., Lahshi V. L., Vipper A. B.(1976) "Ocenka energii aktivacii processa himicheskogo modificirovaniya poverhnostej treniya $\mathrm{v}$ usloviyah granichnoj smazki” Himiya i tehnologiya topliv i masel, №2, S. 50-52.

[23] B. I. Kovalskij, V. G. Shram, Yu. N. Bezborodov, N. N. Malysheva, A. N. Sokolnikov (2013) "Issledovanie vliyaniya produktov temperaturnoj destrukcii na protivoiznosnye svojstva mineralnogo transmissionnogo masla TNK TRANS 80W-85GL4”, Tehnologii nefti i gaza, №2 (85), S.27-35.

[24] Dyha A. V. (2006) "Strukturno - termodinamicheskie podhody v mehanizmah granichnogo smazyvaniya" Problemi tribologiyi (Problems of Tribology), № 3 S.62-65.

[25] Yu. N. Bezborodov, B. I. Kovalskij, N. N. Malysheva, A. N. Sokolnikov, E. G. Malceva (2011) "Metody kontrolya i diagnostiki ekspluatacionnyh svojstv smazochnyh materialov po parametram termookislitelnoj stabilnosti i temperaturnoj stojkosti: monografiya”, Krasnoyarsk:Sib.feder.un-t, 366s.

[26] Y. O. Lyashenko, N. M. Manko (2007) "The Account of Spatial Inhomogeneity of the Temperature in the Synergetic Model of Boundary Friction", J. Nano-Electron. Phys., Vol.5, №3, P.II, 03040 (5pp.). http://jnep.sumdu.edu.ua/download/numbers/2013/3/articles/jn ep_2013_V5_03040.pdf.

[27] B. E. Gurskii, A. V. Chichinadze (2007) "Thermal friction problem and its development: Part 2. The role of heat phenomena in fracture of tooth wheels of cylindrical involute gears of real dimensions", Journal of Friction and Wear, Vol.28, Issue 4, pp. 395-400. 